ORIGINAL ARTICLE

\section{Five-Year Outcomes after Off-Pump or On-Pump Coronary-Artery Bypass Grafting}

\author{
André Lamy, M.D., P.J. Devereaux, M.D., Ph.D., Dorairaj Prabhakaran, M.D., \\ David P. Taggart, Ph.D., Shengshou Hu, M.D., Zbynek Straka, M.D., \\ Leopoldo S. Piegas, M.D., Alvaro Avezum, M.D., Ahmet R. Akar, M.D., \\ Fernando Lanas Zanetti, M.D., Anil R. Jain, M.D., Nicolas Noiseux, M.D., \\ Chandrasekar Padmanabhan, M.D., Juan-Carlos Bahamondes, M.D., \\ Richard J. Novick, M.D., Liang Tao, M.D., Pablo A. Olavegogeascoechea, M.D., \\ Balram Airan, M.D., Toomas-Andres Sulling, M.D., Richard P. Whitlock, M.D., \\ Yongning Ou, M.Sc., Peggy Gao, M.Sc., Shirley Pettit, R.N., \\ and Salim Yusuf, D.Phil., for the CORONARY Investigators*
}

A BSTRACT

\section{BACKGROUND}

We previously reported that there was no significant difference at 30 days or at 1 year in the rate of the composite outcome of death, stroke, myocardial infarction, or renal failure between patients who underwent coronary-artery bypass grafting (CABG) performed with a beating-heart technique (off-pump) and those who underwent CABG performed with cardiopulmonary bypass (on-pump). We now report the results at 5 years (the end of the trial).

\section{METHODS}

A total of 4752 patients (from 19 countries) who had coronary artery disease were randomly assigned to undergo off-pump or on-pump CABG. For this report, we analyzed a composite outcome of death, stroke, myocardial infarction, renal failure, or repeat coronary revascularization (either CABG or percutaneous coronary intervention). The mean follow-up period was 4.8 years.

\section{RESULTS}

There were no significant differences between the off-pump group and the onpump group in the rate of the composite outcome $(23.1 \%$ and $23.6 \%$, respectively; hazard ratio with off-pump CABG, 0.98 ; 95\% confidence interval [CI], 0.87 to 1.10; $\mathrm{P}=0.72$ ) or in the rates of the components of the outcome, including repeat coronary revascularization, which was performed in $2.8 \%$ of the patients in the offpump group and in $2.3 \%$ of the patients in the on-pump group (hazard ratio, 1.21; $95 \% \mathrm{CI}, 0.85$ to $1.73 ; \mathrm{P}=0.29)$. The secondary outcome for the overall period of the trial - the mean cost in U.S. dollars per patient - also did not differ significantly between the off-pump group and the on-pump group $(\$ 15,107$ and $\$ 14,992$, respectively; between-group difference, $\$ 115 ; 95 \% \mathrm{CI},-\$ 697$ to $\$ 927)$. There were no significant between-group differences in quality-of-life measures.

\section{CONCLUSIONS}

In our trial, the rate of the composite outcome of death, stroke, myocardial infarction, renal failure, or repeat revascularization at 5 years of follow-up was similar among patients who underwent off-pump CABG and those who underwent onpump CABG. (Funded by the Canadian Institutes of Health Research; CORONARY ClinicalTrials.gov number, NCT00463294.)
The authors' affiliations are listed in the Appendix. Address reprint requests to Dr. Lamy at the Population Health Research Institute, Hamilton Health Sciences, McMaster University, Hamilton, ON L8L 2X2, Canada, or at lamya@mcmaster.ca.

*A complete list of investigators in the CABG Off or On Pump Revascularization Study (CORONARY) is provided in the Supplementary Appendix, available at NEJM.org.

This article was published on October 23, 2016, at NEJM.org.

N Engl J Med 2016;375:2359-68. DOI: 10.1056/NEJMoal601564 Copyright (๑) 2016 Massachusetts Medical Society. 
ORONARY-ARTERY BYPASS GRAFTING (CABG) reduces the risk of death in patients with extensive coronary artery disease. ${ }^{1}$ CABG is usually performed with the use of a cardiopulmonary bypass (on-pump CABG). With this approach, perioperative mortality is approximately $2 \%$, with an additional 5 to $9 \%$ of patients having myocardial infarction, stroke, or renal failure requiring dialysis. The technique of performing CABG on a beating heart (off-pump CABG) was developed to decrease the risk of perioperative complications and to improve long-term outcomes; some complications, both perioperative and long term, may be related to the use of cardiopulmonary bypass and to cross-clamping of the aorta in association with the on-pump CABG procedure.

Several small trials have compared off-pump CABG and on-pump CABG. ${ }^{2-6}$ Larger trials have also been performed, the largest of which are the CABG Off or On Pump Revascularization Study (CORONARY) (involving 4752 patients), the Randomized On/Off Bypass (ROOBY) trial (involving 2203 patients from the Veterans Affairs medical system), ${ }^{7,8}$ the Danish On-pump versus Off-pump Randomization Study (DOORS) (involving 900 patients from Denmark), ${ }^{9,10}$ and the German OffPump Coronary Artery Bypass Grafting in Elderly Patients (GOPCABE) trial (involving 2539 patients from Germany). ${ }^{11}$ None of these previous trials have reported long-term outcomes.

To evaluate the long-term effects of off-pump versus on-pump CABG, we have now analyzed the 5-year follow-up data from CORONARY, which was conducted in 19 countries. Previously, we reported the 30 -day ${ }^{12}$ and 1 -year ${ }^{13}$ outcomes of the trial. At 1 year, the first coprimary outcome (a composite of death, myocardial infarction, stroke, or new renal failure requiring dialysis) had occurred in similar numbers of patients in each group, but there was a trend toward more frequent repeat revascularizations (percutaneous coronary intervention [PCI] or CABG) in association with off-pump surgery (33 patients [1.4\%] in the off-pump group vs. 20 patients [0.8\%] in the on-pump group; hazard ratio, 1.66; 95\% confidence interval [CI], 0.95 to $2.89 ; \mathrm{P}=0.07$ ).

METHODS

TRIAL DESIGN

CORONARY was a randomized, controlled trial with blinded adjudication of outcomes, in which off-pump CABG and on-pump CABG were compared in patients who were undergoing isolated CABG. The primary hypothesis was that offpump CABG would be associated with fewer major clinical events in the short term (30 days) than on-pump CABG and that the benefits of off-pump CABG would be maintained in the long term (5 years). We have previously published the trial design ${ }^{14}$ and the results at 30 days $^{12}$ and at 1 year. $^{13}$

The trial was designed by the authors and approved by national regulatory authorities and the ethics committee at each participating center. All funding was provided by the Canadian Institutes of Health Research. The data were gathered and analyzed by the Population Health Research Institute (McMaster University, Hamilton, Ontario, Canada). The authors vouch for the accuracy and completeness of the data and all analyses and for the fidelity of the trial to the protocol, which is available with the full text of this article at NEJM.org.

\section{PATIENTS}

Patients who were scheduled to undergo CABG were eligible to participate in the trial if they required isolated $\mathrm{CABG}$ with median sternotomy, provided written informed consent, and had one or more of the following risk factors: an age of 70 years or more, peripheral arterial disease, cerebrovascular disease or carotid stenosis of $70 \%$ or more of the luminal diameter, or renal insufficiency. Patients 60 to 69 years of age were eligible if they had at least one of the following risk factors (and patients 55 to 59 years of age were eligible if they had at least two): diabetes requiring treatment with an oral hypoglycemic agent or insulin, the need for urgent revascularization after an acute coronary syndrome, a left ventricular ejection fraction of less than $35 \%$, or a history of smoking within 1 year before randomization.

\section{QUALIFICATION OF SURGEONS}

To ensure that the surgeons were skilled in the technique assigned, we used the approach of an expertise-based, randomized, controlled trial. ${ }^{15}$ Each procedure was performed by a surgeon who had expertise in the specific type of surgery that the patient was assigned to undergo. Expertise was defined as more than 2 years of experience after residency training and completion of more than 100 cases of the specific technique (either 
on-pump or off-pump CABG). Surgeons who met these criteria for each type of procedure separately were considered to have expertise in both techniques and were allowed to perform both types of CABG during the trial. Trainees were not allowed to be the primary surgeon.

\section{FOLLOW-UP AND TRIAL OUTCOMES}

Study personnel conducted in-person or telephone follow-up with patients or their next of kin (if patients were not available) at 30 days and at 1 year after the procedure and on a yearly basis until the end of the trial. If a patient indicated that any outcome event had occurred, the patient's physician was contacted to obtain source documents regarding the event.

The first coprimary outcome was a composite of death, nonfatal stroke, nonfatal myocardial infarction, or nonfatal new renal failure requiring dialysis at 30 days after randomization. In addition to being used to report results at 30 days, ${ }^{12}$ this outcome was also assessed at 1 year. ${ }^{13}$

The second coprimary outcome was a composite of death, nonfatal stroke, nonfatal myocardial infarction, nonfatal new renal failure requiring dialysis, or repeat coronary revascularization (PCI or $\mathrm{CABG}$ ) at the end of the trial (a mean of 4.8 years after randomization). We now report the results for the second coprimary outcome. All deaths in the first 30 days were considered to be cardiovascular deaths. All reported components of the first and second coprimary outcomes, as well as recurrent angina, were reviewed by an adjudication committee, the members of which were unaware of the treatment assignments. The outcomes as adjudicated by this committee were used in the statistical analyses.

Quality of life was assessed with the use of the European Quality of Life-5 Dimensions questionnaire (EQ-5D) and the EQ-5D visual-analogue scale. The EQ-5D assesses five dimensions of quality of life; the total score ranges from 0 to 1 , with higher scores indicating better quality-oflife status. The EQ-5D visual-analogue scale assesses the respondent's self-rated health on a vertical visual-analogue scale. The total score ranges from 0 to $100 \%$, with higher scores indicating better health status.

In addition to the quality-of-life assessments, neurocognitive tests were performed before the CABG procedure and at discharge, 30 days, and
1 year; the details of the tests and their results have been described previously. ${ }^{13}$ The quality-oflife and neurocognitive tests were optional for both the patients and the investigators at the study sites. Neurocognitive testing was not performed at the 5-year follow-up, and therefore an assessment of neurocognitive status is not included in this report.

\section{ECONOMIC ANALYSIS}

At the end of the trial, we conducted an economic analysis to evaluate the secondary outcome: the cost associated with each type of CABG. We hypothesized in the trial protocol that the use of off-pump CABG would be either cost-neutral or cost-saving as compared with onpump CABG. We reported the results at 1 year. ${ }^{16}$ We have followed the same approach in this report for the results at the end of the trial, with the exception that costs have been adjusted for inflation and we applied an annual discounting of $3 \%$ because the trial spanned many years. All figures are in U.S. currency for 2016.

\section{STATISTICAL ANALYSIS}

All analyses were conducted according to the intention-to-treat principle. We used a time-toevent analysis with a Cox regression to report the long-term outcomes, after testing the assumption of proportional hazards. The time to the first occurrence of any one of the components of the primary outcome was described with the use of Kaplan-Meier survival curves, and the comparisons between the two treatment groups were performed with a log-rank test. The treatment effect is expressed as the hazard ratio with 95\% confidence intervals, which was derived from the Cox proportional-hazards model for the second coprimary outcome at 5 years. The comparison between the two operative techniques was assessed in prespecified subgroups defined by diabetes status, cerebrovascular disease status, left ventricular function, number of diseased vessels, sex, age, body-mass index, region, and European System for Cardiac Operative Risk Evaluation (EuroSCORE) grade, and tests for interaction were performed with the use of a Cox proportional-hazards model. We also undertook landmark analyses to assess these outcomes between 1 year and 5 years, excluding data from patients who had had the outcome evaluated in the first year or who had no follow-up data past 


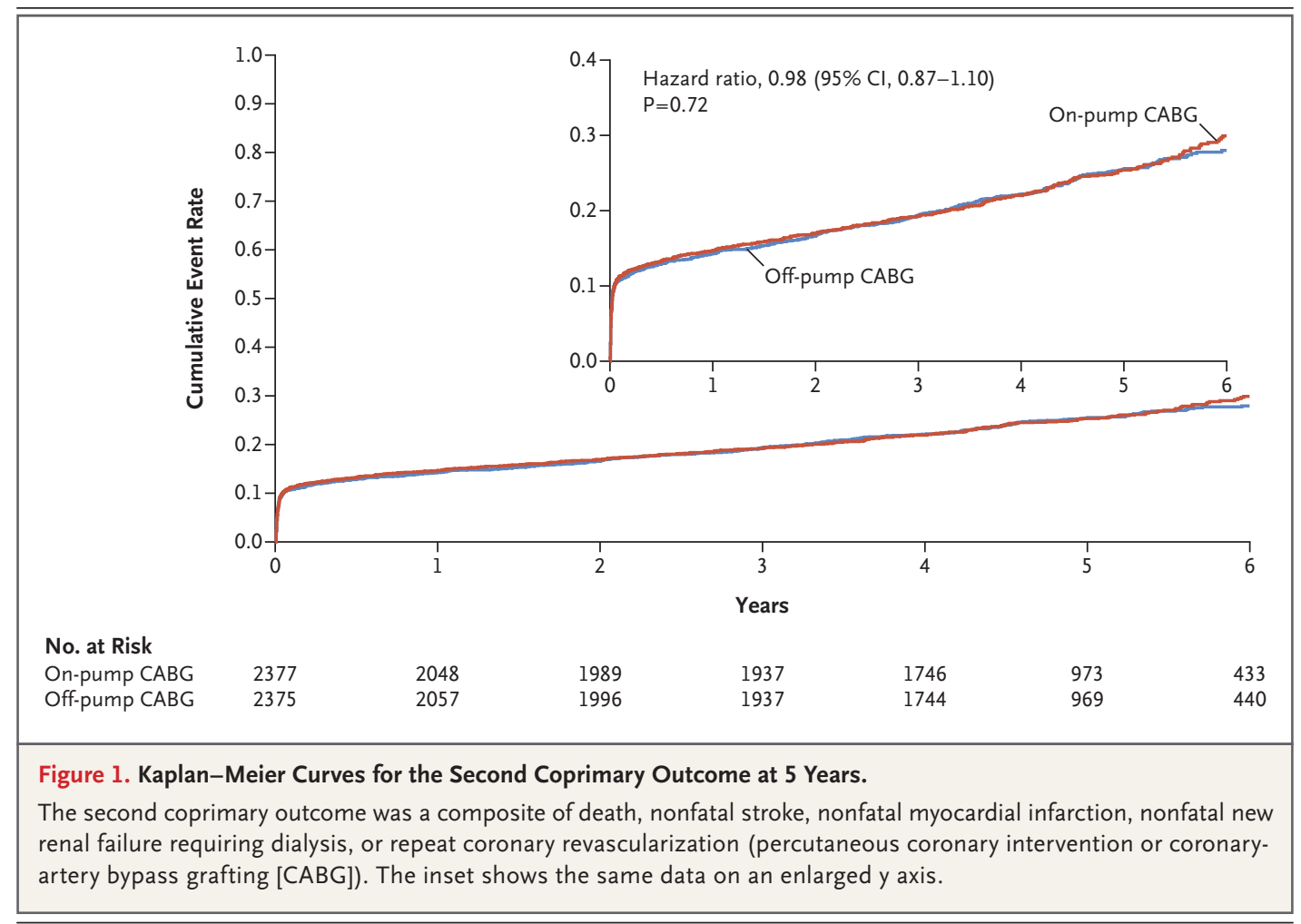

1 year. To analyze the quality-of-life data at each follow-up point (i.e., hospital discharge, 30 days, 1 year, and 5 years), we calculated the changes in assessment scores from baseline to the followup point for each patient, limiting the analysis to patients for whom data were available both at baseline and at the follow-up point being analyzed. The mean value for the change in score was then calculated within each group, ${ }^{17}$ and these means were compared between the two groups.

\section{RESULTS}

\section{PATIENTS}

From November 2006 through October 2011, a total of 4752 patients were enrolled at 79 hospitals in 19 countries on four continents and were randomly assigned to undergo either off-pump CABG (2375 patients) or on-pump CABG (2377 patients). The baseline characteristics of the patients have been reported previously. ${ }^{12}$ At the end of the trial, follow-up data were available for $98.8 \%$ of the patients (see the Supplementary Appendix, available at NEJM.org).

\section{SECOND COPRIMARY OUTCOME}

At a mean of 4.8 years after randomization, a second coprimary outcome event had occurred in 548 patients (23.1\%) in the off-pump group and in 560 patients $(23.6 \%)$ in the on-pump group (hazard ratio with off-pump CABG, 0.98; $95 \%$ CI, 0.87 to $1.10 ; \mathrm{P}=0.72$ ) (Fig. 1 and Table 1). There were no significant between-group differences in the rates of the individual components of this composite outcome, including the rates of repeat revascularization (PCI or CABG), which was performed in 66 patients $(2.8 \%)$ in the offpump group and in 55 patients $(2.3 \%)$ in the on-pump group (hazard ratio, 1.21; 95\% CI, 0.85 to $1.73 ; \mathrm{P}=0.29$ ). In each treatment group, the rate of PCI performed because of graft failure was similar to that of PCI performed because of new lesions (Table S1 in the Supplementary Appendix).

\section{SECONDARY OUTCOME}

During the overall period of the trial, there was no significant between-group difference in the secondary outcome, mean cost per patient ( $\$ 15,107$ in the off-pump group and $\$ 14,992$ in 


\begin{tabular}{|c|c|c|c|c|}
\hline Outcome & $\begin{array}{l}\text { Off-Pump Group } \\
\qquad(\mathrm{N}=2375)\end{array}$ & $\begin{array}{l}\text { On-Pump Group } \\
\qquad(\mathrm{N}=2377)\end{array}$ & $\begin{array}{l}\text { Hazard Ratio } \\
\text { (95\% Cl) }\end{array}$ & P Value \\
\hline Second coprimary outcome - no. (\%)* & $548(23.1)$ & $560(23.6)$ & $0.98(0.87-1.10)$ & 0.72 \\
\hline Death & $346(14.6)$ & $322(13.5)$ & $1.08(0.93-1.26)$ & 0.30 \\
\hline Myocardial infarction & $178(7.5)$ & $194(8.2)$ & $0.92(0.75-1.13)$ & 0.41 \\
\hline Stroke & $55(2.3)$ & $66(2.8)$ & $0.83(0.58-1.19)$ & 0.32 \\
\hline New renal failure requiring dialysis & $40(1.7)$ & $45(1.9)$ & $0.89(0.58-1.37)$ & 0.60 \\
\hline Repeat revascularization $\uparrow$ & $66(2.8)$ & $55(2.3)$ & $1.21(0.85-1.73)$ & 0.29 \\
\hline $\mathrm{PCl}$ & $59(2.5)$ & $52(2.2)$ & $1.15(0.79-1.66)$ & 0.48 \\
\hline CABG & $9(0.4)$ & $4(0.2)$ & $2.27(0.70-7.38)$ & 0.17 \\
\hline \multicolumn{5}{|l|}{ Nonprespecified outcomes — no. (\%) } \\
\hline Cardiovascular death & $237(10.0)$ & $230(9.7)$ & $1.04(0.87-1.24)$ & 0.69 \\
\hline Repeat coronary angiography & $125(5.3)$ & $114(4.8)$ & $1.11(0.86-1.43)$ & 0.43 \\
\hline Recurrent angina & $41(1.7)$ & $39(1.6)$ & $1.05(0.68-1.63)$ & 0.81 \\
\hline $\begin{array}{l}\text { Primary outcome in per-protocol population } \\
\qquad- \text { no./total no. (\%) } \mathbb{}\end{array}$ & $487 / 2148(22.7)$ & 499/2182 (22.9) & $0.99(0.87-1.12)$ & 0.86 \\
\hline \multicolumn{5}{|c|}{$\begin{array}{l}\text { * The second coprimary outcome was a composite of death, nonfatal stroke, nonfatal myocardial infarction, new renal } \\
\text { failure requiring dialysis, and repeat revascularization (percutaneous coronary intervention [PCI] or coronary-artery by- } \\
\text { pass grafting [CABG]). } \\
\text { Some patients had CABG and a PCI. } \\
\text { SAll deaths in the first } 30 \text { days were considered to be cardiovascular deaths. } \\
\text { I The per-protocol population included patients who underwent the randomly assigned procedure (i.e., without crossing } \\
\text { over to the other procedure). }\end{array}$} \\
\hline
\end{tabular}

the on-pump group; difference, $\$ 115$; $95 \% \mathrm{CI}$, $-\$ 697$ to $\$ 927)$. There were no significant differences between the two groups at any point during the trial or in any of the categories of costs (Table 2). The between-group difference in discounted costs was also not significant (difference, $\$ 96 ; 95 \% \mathrm{CI},-\$ 607$ to $\$ 799$ ).

\section{QUALITY-OF-LIFE OUTCOMES}

A total of 2845 patients initially agreed to provide data for the substudy of quality of life. There was a small decline in quality of life, as measured with the EQ-5D and the EQ-5D visualanalogue scale, in both groups at the time of discharge (Table 3), but this was followed by a sharp increase in quality of life as perceived by patients in both groups at 30 days, and this higher quality of life was sustained to the end of the trial. There was no significant difference between the two groups in quality-of-life scores at any time point. Very similar results were found for the 1531 patients who provided data at all follow-up points (Table S2 in the Supplementary Appendix).

\section{NON PRESPECIFIED OUTCOMES}

The rate of repeat coronary angiography was similar in the two groups $(5.3 \%$ in the off-pump group and $4.8 \%$ in the on-pump group; hazard ratio, $1.11 ; 95 \% \mathrm{CI}, 0.86$ to $1.43 ; \mathrm{P}=0.43$ ) (Table 1). In the majority of cases, angiography was performed because of ischemic symptoms or suspected myocardial infarction (Table S3 in the Supplementary Appendix). The rate of recurrent angina was also similar in the two groups $(1.7 \%$ in the off-pump group and $1.6 \%$ in the on-pump group; hazard ratio, 1.05; 95\% CI, 0.68 to 1.63; $\mathrm{P}=0.81$ ), as was the rate of the primary outcome among patients who underwent the assigned procedure (i.e., without crossing over to the other procedure) $(22.7 \%$ in the off-pump group and $22.9 \%$ in the on-pump group; hazard ratio, 0.99; $95 \% \mathrm{CI}, 0.87$ to $1.12 ; \mathrm{P}=0.86$ ) (Table 1 ).

In the landmark analysis of the data between 1 year and 4.8 years, the rate of the primary outcome was found to be similar in the two groups $(11.3 \%$ and $11.5 \%$; hazard ratio, 0.98 ; 95\% CI, 0.82 to $1.18 ; \mathrm{P}=0.86$ ) (Table S4 in the Supplementary Appendix). Landmark analyses 


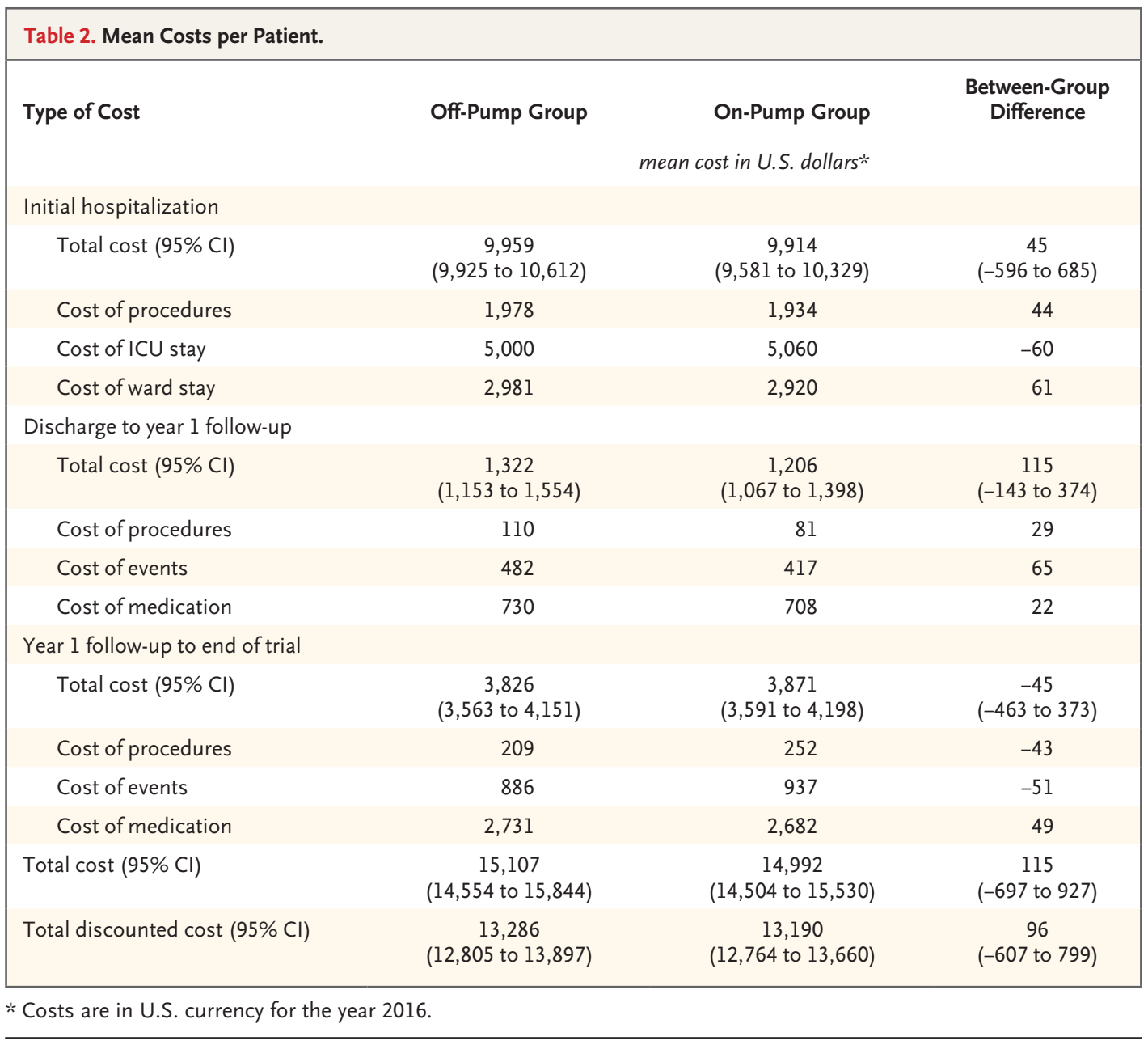

also showed that the rates of repeat revascularization (PCI or CABG) were similar in the two groups $(1.5 \%$ in both treatment groups; hazard ratio, $1.01 ; 95 \% \mathrm{CI}, 0.61$ to $1.65 ; \mathrm{P}=0.98$ ), as were the rates of repeat coronary angiography (3.7\% in both treatment groups; hazard ratio, 1.00 ; $95 \% \mathrm{CI}, 0.73$ to $1.38 ; \mathrm{P}=0.98$ ) and recurrent angina $(1.0 \%$ in the off-pump group and $0.9 \%$ in the on-pump group; hazard ratio, 1.16; $95 \% \mathrm{CI}, 0.62$ to $2.19 ; \mathrm{P}=0.64)$.

\section{SUBGROUP ANALYSIS}

To test the consistency and validity of our results, we examined the treatment effects in various subgroups. No significant interactions were seen between the CABG procedure and any of the subgroup variables, with the exception of diabetes status (Fig. 2, and Table S5 in the Supplementary Appendix). At 4.8 years after randomization, among patients with diabetes, the second coprimary outcome had occurred in 250 patients $(22.7 \%)$ in the off-pump group and in $294 \mathrm{pa}$ tients $(26.1 \%)$ in the on-pump group (hazard ratio, $0.85 ; 95 \% \mathrm{CI}, 0.72$ to $1.01 ; \mathrm{P}=0.06$ ). Among the patients who did not have diabetes, the second coprimary outcome occurred in 298 patients (23.4\%) in the off-pump group and in 266 patients $(21.3 \%)$ in the on-pump group (hazard ratio, 1.12; $95 \% \mathrm{CI}, 0.95$ to $1.32 ; \mathrm{P}=0.19$ ) $(\mathrm{P}=0.02$ for the interaction [not corrected for multiple testing]).

\section{DISCUSSION}

In CORONARY, we compared off-pump CABG with on-pump CABG in 4752 participants from 19 countries on four continents. At a mean of 4.8 years of follow-up, we found no significant 


\begin{tabular}{|c|c|c|c|c|c|}
\hline \multicolumn{6}{|c|}{ Table 3. Quality-of-Life Results.* } \\
\hline \multirow[t]{2}{*}{ Measure } & \multicolumn{2}{|c|}{ Off-Pump Group } & \multicolumn{2}{|c|}{ On-Pump Group } & \multirow[t]{2}{*}{ P Value } \\
\hline & $\begin{array}{l}\text { No. of } \\
\text { Patients }\end{array}$ & Score & $\begin{array}{l}\text { No. of } \\
\text { Patients }\end{array}$ & Score & \\
\hline \multicolumn{6}{|l|}{ EQ-5D广े } \\
\hline Baseline & 1424 & $0.77 \pm 0.22$ & 1421 & $0.77 \pm 0.22$ & 0.97 \\
\hline \multicolumn{6}{|c|}{ Change from baseline } \\
\hline To discharge & 1265 & $-0.03 \pm 0.28$ & 1251 & $-0.03 \pm 0.26$ & 0.75 \\
\hline To 30 days & 1154 & $0.07 \pm 0.26$ & 1161 & $0.08 \pm 0.25$ & 0.25 \\
\hline To $1 \mathrm{yr}$ & 1045 & $0.13 \pm 0.25$ & 1055 & $0.15 \pm 0.24$ & 0.26 \\
\hline To end of trial & 1059 & $0.12 \pm 0.25$ & 1071 & $0.13 \pm 0.26$ & 0.28 \\
\hline \multicolumn{6}{|c|}{ EQ-5D visual-analogue scale: } \\
\hline Baseline & 1423 & $65.8 \pm 17.6$ & 1422 & $66.6 \pm 17.8$ & 0.24 \\
\hline \multicolumn{6}{|c|}{ Change from baseline } \\
\hline To discharge & 1264 & $1.8 \pm 18.2$ & 1250 & $1.0 \pm 17.8$ & 0.27 \\
\hline To 30 days & 1154 & $8.5 \pm 17.6$ & 1159 & $8.0 \pm 17.6$ & 0.44 \\
\hline To 1 year & 1044 & $11.3 \pm 17.9$ & 1055 & $11.5 \pm 17.6$ & 0.86 \\
\hline To end of trial & 1055 & $10.4 \pm 20.4$ & 1069 & $10.4 \pm 20.9$ & 0.99 \\
\hline
\end{tabular}

* Plus-minus values are means \pm SD. The number of patients at baseline is the number of patients who performed the baseline test. The number of patients at each subsequent time is the number of patients who performed the test both at baseline and at that specific time.

$\dagger$ The European Quality of Life-5 Dimensions questionnaire (EQ-5D) assesses five dimensions of quality of life. The total score ranges from 0 to 1 , with higher scores indicating better quality-of-life status.

7 The EQ-5D visual-analogue scale assesses the respondent's self-rated health on a vertical visual-analogue scale. The total score ranges from 0 to $100 \%$, with higher scores indicating better status.

difference between the groups in the second coprimary outcome of death, nonfatal stroke, nonfatal myocardial infarction, nonfatal new renal failure requiring dialysis, or repeat revascularization (PCI or CABG) and no significant difference in any component of the second coprimary outcome. In addition, we found no significant differences between the two techniques with regard to rates of recurrent angina, repeat angiography, repeat revascularization (PCI or CABG), or cardiovascular death, as well as no significant differences in cost or quality of life.

Investigators from three small trials ${ }^{18-20}$ involving a total of 768 patients with 5 years of followup data have also published their long-term results, and they found no significant differences between the two techniques. However, some nonrandomized trials have reported lower rates of long-term survival ${ }^{21,22}$ in association with offpump CABG, as well as higher rates of repeat revascularization. ${ }^{23,24}$ On the basis of these re- sults, some authors ${ }^{25,26}$ have recommended that off-pump CABG be abandoned. Although at 30 days in CORONARY, fewer grafts had been performed in the off-pump group, and the off-pump group had had a higher rate of crossover to the other procedure (relative risk, 1.23; 95\% CI, 1.00 to $1.50 ; \mathrm{P}=0.06$ ) and a higher rate of incomplete revascularization (relative risk, 1.18; 95\% CI, 1.0 to 1.39; $\mathrm{P}=0.05),{ }^{12}$ at 5 years there was no significant difference in any outcome between the two techniques, even among patients who crossed over to the other procedure or received an incomplete revascularization during their CABG procedure (Table S6 in the Supplementary Appendix).

We found an apparent differential effect of the two approaches to surgery according to whether patients had diabetes. Although diabetes status was a prespecified subgroup variable at the inception of the trial, we did not specify a reason to expect a difference between the treatment groups. Our intention was to examine the con- 


\begin{tabular}{|c|c|c|c|c|}
\hline \multirow[t]{2}{*}{ Subgroup } & $\begin{array}{l}\text { Off-Pump } \\
\text { CABG }\end{array}$ & $\begin{array}{l}\text { On-Pump } \\
\text { CABG }\end{array}$ & Hazard Ratio $(95 \% \mathrm{Cl})$ & $\begin{array}{l}\text { P Value for } \\
\text { Interaction }\end{array}$ \\
\hline & \multicolumn{2}{|c|}{ no. of patients/total no. (\%) } & & \\
\hline \multicolumn{3}{|l|}{ Diabetes } & & 0.02 \\
\hline Yes & $250 / 1100$ (22.7) & $294 / 1128(26.1)$ & $-\mathrm{n}$ & $0.85(0.72-1.01)$ \\
\hline No & $298 / 1275(23.4)$ & $266 / 1248(21.3)$ & + & $1.12(0.95-1.32)$ \\
\hline \multicolumn{2}{|l|}{ Sex } & & & 0.43 \\
\hline Male & $424 / 1901(22.3)$ & $435 / 1942(22.4)$ & & $1.00(0.87-1.14)$ \\
\hline Female & $124 / 474(26.2)$ & $125 / 434(28.8)$ & $\rightarrow$ & $0.89(0.70-1.15)$ \\
\hline \multicolumn{2}{|l|}{ Cerebrovascular disease } & & & 0.16 \\
\hline Yes & $73 / 215(34.0)$ & $68 / 241(28.2)$ & $\frac{1}{1}$ & $1.24(0.89-1.72)$ \\
\hline No & $475 / 2160(22.0)$ & $492 / 2136(23.0)$ & +1 & $0.95(0.84-1.08)$ \\
\hline \multicolumn{2}{|l|}{ Age } & & & 0.36 \\
\hline$<70 \mathrm{yr}$ & $278 / 1407(19.8)$ & $271 / 1408(19.2)$ & + & $1.03(0.87-1.22)$ \\
\hline$\geq 70 \mathrm{yr}$ & $270 / 967(27.9)$ & $289 / 968$ (29.9) & - & $0.92(0.78-1.09)$ \\
\hline \multicolumn{2}{|l|}{ EuroSCORE } & & & 0.53 \\
\hline $0-2$ & $115 / 679(16.9)$ & $102 / 660(15.5)$ & in- & $1.11(0.85-1.45)$ \\
\hline $3-5$ & $283 / 1229(23.0)$ & $308 / 1287(23.9)$ & & $0.96(0.81-1.12)$ \\
\hline$>5$ & $140 / 429(32.6)$ & $139 / 399(34.8)$ & -1 & $0.91(0.72-1.16)$ \\
\hline \multicolumn{2}{|l|}{ Region } & & & 0.66 \\
\hline South America & $114 / 424(26.9)$ & $123 / 419(29.4)$ & $\rightarrow$ & $0.89(0.69-1.15)$ \\
\hline North America, Australia, Europe & $254 / 908(28.0)$ & $268 / 913(29.4)$ & -1 & $0.95(0.80-1.13)$ \\
\hline India & $111 / 653(17.0)$ & $109 / 654(16.7)$ & - & $1.03(0.79-1.34)$ \\
\hline China & $69 / 390(17.7)$ & $60 / 391(15.3)$ & $\rightarrow$ & $1.16(0.82-1.63)$ \\
\hline \multicolumn{2}{|l|}{ Body-mass index } & & & 0.97 \\
\hline $16.0-24.9$ & $180 / 847(21.3)$ & $192 / 890(21.6)$ & $-\frac{1}{1}$ & $1.00(0.82-1.23)$ \\
\hline $25.0-27.9$ & $153 / 726(21.1)$ & $145 / 667(21.7)$ & 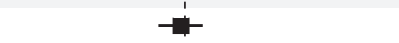 & $0.96(0.76-1.20)$ \\
\hline $28.0-44.9$ & $203 / 767(26.5)$ & $211 / 794(26.6)$ & -1 & $0.99(0.82-1.20)$ \\
\hline \multicolumn{2}{|l|}{ Left ventricular ejection fraction } & & & 0.13 \\
\hline$\geq 50 \%$, grade 1 & $350 / 1643(21.3)$ & $343 / 1651(20.8)$ & + & $1.03(0.89-1.19)$ \\
\hline $35-49 \%$, grade 2 & $134 / 560(23.9)$ & $152 / 543(28.0)$ & $\rightarrow+1$ & $0.83(0.65-1.04)$ \\
\hline $20-34 \%$, grade 3 & $40 / 118(33.9)$ & $48 / 126(38.1)$ & $\rightarrow-1$ & $0.85(0.56-1.29)$ \\
\hline$<20 \%$, grade 4 & $4 / 6(66.7)$ & $1 / 5(20.0)$ & $\longrightarrow$ & $5.61(0.61-51.60)$ \\
\hline \multicolumn{2}{|l|}{ Diseased vessels } & & & 0.39 \\
\hline Left main & $123 / 514(23.9)$ & $128 / 487(26.3)$ & $\rightarrow$ & $0.88(0.69-1.13)$ \\
\hline Triple & $305 / 1306(23.4)$ & $325 / 1405(23.1)$ & $-\frac{1}{1}$ & $1.01(0.86-1.18)$ \\
\hline Double & $89 / 436(20.4)$ & $78 / 381(20.5)$ & $\rightarrow-$ & $1.01(0.74-1.37)$ \\
\hline Single & $9 / 70(12.9)$ & $12 / 49(24.5)$ & $\longrightarrow$ & $0.50(0.21-1.20)$ \\
\hline \multicolumn{2}{|l|}{$\begin{array}{l}\text { Operator experience with off-pump } \\
\text { CABG }\end{array}$} & & & 0.48 \\
\hline$<350$ cases, lower third & $149 / 723(20.6)$ & $175 / 769(22.8)$ & $\rightarrow$ & $0.90(0.72-1.12)$ \\
\hline 350-900 cases, middle third & $185 / 782(23.7)$ & $197 / 795(24.8)$ & $\rightarrow$ & $0.94(0.77-1.15)$ \\
\hline \multirow[t]{3}{*}{$>900$ cases, highest third } & $203 / 836(24.3)$ & $180 / 775(23.2)$ & $i$ & $1.07(0.87-1.31)$ \\
\hline & & 0.0 & $0.2 \quad 0.4$ & \\
\hline & & Off-Pum & On-Pump CABG & \\
\hline \multicolumn{5}{|c|}{ Figure 2. Hazard Ratios for the Second Coprimary Outcome in Prespecified Subgroups. } \\
\hline \multicolumn{5}{|c|}{$\begin{array}{l}\text { Grades of } 0 \text { to } 2 \text { on the European System for Cardiac Operative Risk Evaluation (EuroSCORE) for CABG indicate low risk; } 3 \text { to } 5 \text {, moder- } \\
\text { ate risk; and more than } 5 \text {, high risk. The body-mass index is the weight in kilograms divided by the square of the height in meters. }\end{array}$} \\
\hline
\end{tabular}

sistency of effects of the two types of CABG and suggesting that there may be an interaction bewas motivated by the results of trials of CABG tween CABG type and diabetes status should be (mostly on-pump) versus PCI in which CABG viewed in light of the fact that we did examine was found to be superior to PCI, particularly several other prespecified subgroups and that so among patients with diabetes. ${ }^{27,28}$ Our results far none of the other trials have reported a sig- 
nificant interaction with this variable. Our results should stimulate a systematic analysis of data from all other trials on the relative longterm effect of the two techniques according to diabetes status. Therefore, until further confirmation is available from other trials, caution should be exercised in interpreting this subgroup result.

It is not surprising that the results of our cost analysis reflect the results of the primary analysis, with no significant differences between the treatment groups: off-pump CABG cost only $\$ 96$ more than on-pump CABG (discounted), a difference that is neither statistically nor financially significant. Therefore, we did not perform a standard cost-effectiveness analysis. One important limitation of our cost analysis is the fact that the specific costs of CABG supplies (off-pump retractors or cardiopulmonary bypass circuits) were not included. Hospitals keep the costs of CABG supplies confidential, and we were not able to obtain those data. The costs of CABG supplies for each technique are generally made similar within each hospital by various vendors. Although cardiopulmonary bypass circuits are not reusable, some reusable off-pump retractors are available on the market, and the use of these retractors for off-pump CABG rather than the nonreusable cardiopulmonary bypass circuits for on-pump CABG could generate important savings.

The quality-of-life and neurocognitive tests were optional. We were unable to provide an assessment of neurocognitive status at the end of the trial. We made a decision to forgo the preplanned neurocognitive testing at the final follow-up for three reasons: we had encountered substantial difficulties in obtaining 1-year neurocognitive testing data (e.g., among the three tests evaluated, the highest completion rate was $61 \%$ at 1 year), ${ }^{13}$ we recognized that obtaining face-to-face follow-up data for neurocognitive testing at 5 years was likely to be even more difficult than at 1 year, and we had limited resources. Participation in the quality-of-life assessment was better, but some patients who chose not to participate initially or who declined to participate later during the follow-up period might have differed in some ways from those who did participate. Various sensitivity analyses suggested that the results were robust and indicated little difference, if any, in quality of life between the patients in the two groups. It is a testimony to CABG surgery that the increase in the quality of life observed after surgery was maintained to the end of the trial.

Our trial has some limitations, as described previously. ${ }^{12,13}$ However, our trial emphasizes the importance of long-term follow-up in surgical trials and indicates that new surgical techniques should be subject to rigorous comparative and large randomized trials before they are adopted widely in practice.

In conclusion, we conducted a large, randomized trial to compare the outcomes of on-pump CABG with those of off-pump CABG. At 5 years, we found no significant difference between the two groups in the rate of death, nonfatal stroke, nonfatal myocardial infarction, or nonfatal new renal failure requiring dialysis or in the rate of subsequent revascularization procedures. We also found no significant difference in cost or quality of life between the two techniques. Our trial results indicate that both procedures are equally effective and safe.

Supported by the Canadian Institutes of Health Research. Dr. Devereaux reports receiving grant support from Abbott Diagnostics, Boehringer Ingelheim, Covidien, Octapharma, Roche Diagnostics, and Stryker. No other potential conflict of interest relevant to this article was reported.

Disclosure forms provided by the authors are available with the full text of this article at NEJM.org.

\section{APPENDIX}

The authors' affiliations are as follows: the Population Health Research Institute, Hamilton Health Sciences, McMaster University, Hamilton, ON (A.L., P.J.D., R.P.W., Y.O., P.G., S.P., S.Y.), Centre Hospitalier de l'Université de Montréal, Montreal (N.N.), and the University of Calgary, Calgary, AB (R.J.N.) - all in Canada; the Center for Chronic Disease Control, Gurgaon (D.P.), SAL Hospital, Ahmedabad (A.R.J.), G. Kuppuswamy Naidu Memorial Hospital, Coimbatore (C.P.), and All India Institute of Medical Sciences, New Delhi (B.A.) - all in India; the University of Oxford, Oxford, United Kingdom (D.P.T.); Fu Wai Cardiovascular Hospital, Xicheng District, Beijing (S.H.), and Wuhan Asia Heart Hospital, Wuhan (L.T.) - both in China; Third Faculty of Medicine Charles University, University Hospital Kralovske Vinohrady, Prague, Czech Republic (Z.S.); Instituto Dante Pazzanese de Cardiologia, São Paulo (L.S.P., A.A.); Ankara University School of Medicine, Ankara, Turkey (A.R.A.); Hospital Regional de Temuco and Universidad de la Frontera, Temuco, Chile (F.L.Z., J.-C.B.); Fundación Médica de Río Negro y Neuquén, Rio Negro, Argentina (P.A.O.); and North Estonia Medical Center, Tallinn, Estonia (T.-A.S.). 
REFERENCES

1. Yusuf S, Zucker D, Peduzzi P, et al. Effect of coronary artery bypass graft surgery on survival: overview of 10 -year results from randomised trials by the Coronary Artery Bypass Graft Surgery Trialists Collaboration. Lancet 1994;344: 563-70.

2. Sellke FW, DiMaio JM, Caplan LR, et al. Comparing on-pump and off-pump coronary artery bypass grafting: numerous studies but few conclusions: a scientific statement from the American Heart Association Council on Cardiovascular Surgery and Anesthesia in collaboration with the Interdisciplinary Working Group on Quality of Care and Outcomes Research. Circulation 2005;111:2858-64.

3. Puskas JD, Williams WH, Mahoney EM, et al. Off-pump vs conventional coronary artery bypass grafting: early and 1-year graft patency, cost, and quality-oflife outcomes: a randomized trial. JAMA 2004;291:1841-9.

4. Nathoe HM, van Dijk D, Jansen EW, et al. A comparison of on-pump and offpump coronary bypass surgery in low-risk patients. N Engl J Med 2003;348:394402.

5. Légaré JF, Buth KJ, King S, et al. Coronary bypass surgery performed off pump does not result in lower in-hospital morbidity than coronary artery bypass grafting performed on pump. Circulation 2004; 109:887-92.

6. Straka Z, Widimsky P, Jirasek K, et al. Off-pump versus on-pump coronary surgery: final results from a prospective randomized study PRAGUE-4. Ann Thorac Surg 2004;77:789-93.

7. Novitzky D, Shroyer AL, Collins JF, et al. A study design to assess the safety and efficacy of on-pump versus off-pump coronary bypass grafting: the ROOBY trial. Clin Trials 2007;4:81-91.

8. Shroyer AL, Grover FL, Hattler B, et al. On-pump versus off-pump coronary-artery bypass surgery. N Engl J Med 2009;361: 1827-37.

9. Houlind K, Kjeldsen BJ, Madsen SN, et al. On-pump versus off-pump coronary artery bypass surgery in elderly patients: results from the Danish On-pump versus Off-pump Randomization Study. Circulation 2012;125:2431-9.

10. Houlind K, Kjeldsen BJ, Madsen SN et al. The impact of avoiding cardiopulmonary by-pass during coronary artery bypass surgery in elderly patients: the Danish On-pump Off-pump Randomisation Study (DOORS). Trials 2009;10:47.

11. Diegeler A, Börgermann J, Kappert U, et al. Off-pump versus on-pump coronaryartery bypass grafting in elderly patients N Engl J Med 2013;368:1189-98.

12. Lamy A, Devereaux PJ, Prabhakaran D, et al. Off-pump or on-pump coronaryartery bypass grafting at 30 days. $\mathrm{N}$ Engl J Med 2012;366:1489-97.

13. Lamy A, Devereaux PJ, Prabhakaran $D$, et al. Effects of off-pump and on-pump coronary-artery bypass grafting at 1 year. N Engl J Med 2013;368:1179-88.

14. Lamy A, Devereaux PJ, Prabhakaran $\mathrm{D}$, et al. Rationale and design of the Coronary Artery Bypass Grafting Surgery Off or On Pump Revascularization Study: a large international randomized trial in cardiac surgery. Am Heart J 2012;163:1-6. 15. Devereaux PJ, Bhandari M, Clarke $M$ et al. Need for expertise based randomised controlled trials. BMJ 2005;330: 88.

16. Lamy A, Tong W, Devereaux PJ, et al. The cost implications of off-pump versus on-pump coronary artery bypass graft surgery at one year. Ann Thorac Surg 2014; 98:1620-5.

17. Saczynski JS, Marcantonio ER, Quach L, et al. Cognitive trajectories after postoperative delirium. N Engl J Med 2012; 367:30-9.

18. van Dijk D, Spoor M, Hijman R, et al. Cognitive and cardiac outcomes 5 years after off-pump vs on-pump coronary artery bypass graft surgery. JAMA 2007;297: 701-8.

19. Hueb W, Lopes NH, Pereira AC, et al. Five-year follow-up of a randomized comparison between off-pump and on-pump stable multivessel coronary artery bypass grafting: the MASS III Trial. Circulation 2010;122:Suppl:S48-S52.

20. Puskas JD, Williams WH, O'Donnell $\mathrm{R}$, et al. Off-pump and on-pump coronary artery bypass grafting are associated with similar graft patency, myocardial ischemia, and freedom from reintervention: long-term follow-up of a randomized trial. Ann Thorac Surg 2011;91:1836-42.

21. Kim JB, Yun S-C, Lim JW, et al. Longterm survival following coronary artery bypass grafting: off-pump versus on-pump strategies. J Am Coll Cardiol 2014;63: 2280-8.

22. Alukayli M, Buth K, Legare J. Offpump CABG surgery is associated with a worse long term mortality than on-pump CABG: result from a randomized trial comparing grafting strategies. Can J Cardiol 2015;31:S110.

23. Hannan EL, Wu C, Smith CR, et al. Off-pump versus on-pump coronary artery bypass graft surgery: differences in shortterm outcomes and in long-term mortality and need for subsequent revascularization. Circulation 2007;116:1145-52.

24. Hu S, Zheng Z, Yuan X, et al. Increasing long-term major vascular events and resource consumption in patients receiving off-pump coronary artery bypass: a singlecenter prospective observational study. Circulation 2010;121:1800-8.

25. Lazar HL. Should off-pump coronary artery bypass grafting be abandoned? Circulation 2013;128:406-13.

26. Sabik J. Should off-pump CABG be abandoned? CTSNet. April 27, 2016 (http:// www.ctsnet.org/article/should-pump-cabg -be-abandoned)

27. Head SJ, Davierwala PM, Serruys PW, et al. Coronary artery bypass grafting vs. percutaneous coronary intervention for patients with three-vessel disease: final fiveyear follow-up of the SYNTAX trial. Eur Heart J 2014;35:2821-30.

28. Farkouh ME, Domanski M, Sleeper LA, et al. Strategies for multivessel revascularization in patients with diabetes. N Engl J Med 2012;367:2375-84.

Copyright (c) 2016 Massachusetts Medical Society. 